Canadian

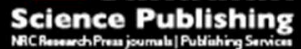

Canadian Journal of Forest Research Revue canadienne de recherche forestière

\title{
Public use of Information about Smoke Emissions: Application of the Risk Information Seeking and Processing (RISP) model
}

\begin{tabular}{|r|l|}
\hline Journal: & Canadian Journal of Forest Research \\
\hline Manuscript ID & cjfr-2017-0099.R1 \\
\hline Danuscript Type: & Article \\
\hline Complete List of Authors: & $\begin{array}{l}\text { Rose, Kathleen; University of Wisconsin Madison, Department of Life } \\
\text { Sciences Communication } \\
\text { Toman, Eric; Ohio State University, School of Environment and Natural } \\
\text { Resources } \\
\text { Olsen, Christine; Oregon State University, Forest Ecosystems and Society }\end{array}$ \\
\hline Keyword: & $\begin{array}{l}\text { prescribed fire, public perceptions, wildfire, Wildland Urban Interface, } \\
\text { Smoke management }\end{array}$ \\
\hline $\begin{array}{r}\text { Is the invited manuscript for } \\
\text { consideration in a Special } \\
\text { Issue? : }\end{array}$ & N/A \\
\hline \multicolumn{2}{|c}{} \\
\hline
\end{tabular}


3 Public use of Information about Smoke Emissions: Application of the Risk Information

$4 \quad$ Seeking and Processing (RISP) model

$7 \quad$ Kathleen M. Rose ${ }^{\mathrm{A} D}$

8 Eric Toman ${ }^{\mathrm{B}}$

9 Christine S. Olsen ${ }^{\mathrm{C}}$

12 A Department of Life Sciences Communication, University of Wisconsin-Madison

13 B School of Environment and Natural Resources, Ohio State University

$14{ }^{\mathrm{C}}$ Forest Ecosystems and Society, Oregon State University

$15 \quad{ }^{D}$ Corresponding author: Email: kmrose@wisc.edu

20 Additional keywords prescribed fire, public perceptions, wildfire, Wildland Urban Interface,

21 smoke management 


\section{Abstract}

23 In the last few decades, the number of people living in fire prone ecosystems has increased,

24 placing more people and private property at risk to future fire events. Substantial research has

25 demonstrated consistent public support for the use of prescribed fires in fuels reduction efforts;

26 however, continuing public concern regarding smoke emissions and negative air quality impacts

27 exists. To date, limited research has specifically examined public attitudes toward smoke

28 emissions. In this study, we use a mail-back/internet survey to assess citizen information seeking

29 behaviors regarding smoke emissions in four communities in high fire risk areas. Path analysis

30 was used to apply the Risk Information Seeking and Processing (RISP) model to examine factors

31 that motivate people to seek information relevant to smoke emissions. We find that residents

32 were concerned about smoke emissions and believed they needed more information. Residents'

33 intentions to seek information were influenced by information (in)sufficiency, the number of

34 sources used, and smoke acceptability, among other factors. Findings suggest that currently

35 available information resources on smoke may not be sufficient to meet residents' information

36 needs, particularly for those most motivated to learn more about emissions. 


\section{Introduction}

Smoke emissions from prescribed and wildfires are an important issue for many Wildland Urban Interface (WUI) residents. Over the last two decades, the number of acres treated by prescribed fires in the United States (US) has increased (NIFC, 2016), while some regions have also seen increases in the number of acres burned by wildland fires (NIFC, 2016). These regional increases may in part be attributed to the lengthening of the fire season, a problem likely to be exacerbated in some areas due to the effects of climate change (Doerr and Santín 2016). Over this same period, the WUI population has also grown (Hammer et al. 2009; Radeloff et al. 2005), resulting in larger numbers of residents that may experience smoke emissions. Among other outcomes, smoke emissions can cause irritated sinuses, coughing, and headaches among exposed populations, impacts of particular significance for the approximately $30 \%$ of WUI households which contain members with health problems that may be worsened by smoke (McCaffrey and Olsen 2012). How these local residents perceive the management of smoke emissions is likely to be an important influence in the continued support for the use of prescribed fires. Should WUI residents decide the negative costs associated with smoke emissions outweigh the benefits offered by prescribed burns, it may become difficult for land managers to implement prescribed burns in the area (Weisshaupt et al. 2005). prescribed fire use and smoke emissions, as well as manage perceptions and potential impacts on nearby populations. These resource managers also point to communication challenges, including uncertainty about the effectiveness of potential communication strategies and inconsistency in messages from different sources regarding smoke emissions (Olsen et al. 2014). Additionally, there is a growing awareness that simply providing information to members of the public 
62 (knowledge deficit approach) does not necessarily lead to better decision-making or greater

63 support for science (Brossard and Lewenstein 2010). Rather, managers must be aware of the

64 needs and concerns of residents to engage effectively about smoke emissions. Substantial

65 research has found that risk perceptions can be affected, either positively or negatively, by the

66 provision of information designed to evoke specific feelings (e.g., Keller et al. 2006; Slovic et al.

67 2004). For instance, Keller et al. (2006) found that risk perceptions can be exacerbated by

68 providing information that results in negative emotions or causes the consideration or recall of

69 potential negative outcomes. However, while previous work has addressed the impact of

70 information provision, limited research has examined the factors that motivate residents to seek

71 information about smoke emissions. The purpose of this paper is to begin to address this

72 research gap using the framework provided by the Risk Information Seeking and Processing

73 (RISP) model.

75 Perceptions of prescribed fires and smoke emissions

76 One common approach to managing perceptions of smoke emissions is by providing

77 information regarding the benefits of prescribed fires, actions taken by fire managers to reduce

78 smoke emissions, or potential behaviors that residents may adopt to minimize the impact of

79 emissions, among others. Substantial prior research has found that acceptance of fuel treatments

80 is positively associated with greater understanding of the treatment and its likely outcomes (e.g.,

81 Blanchard and Ryan 2007; McCaffrey 2004; Shindler and Toman 2003). Moreover, outreach

82 programs, based in a diversity of approaches to science communication (Brossard and

83 Lewenstein 2010), have contributed to more supportive beliefs and attitudes toward the use of 
84 prescribed fires among local residents (e.g., Bright et al. 2007; McCaffrey 2004, 2006; Toman et 85 al. 2006).

87 some studies have also identified concern regarding smoke emissions (e.g., Brunson and Evans 88 2005; Shindler and Toman 2003). Similarly, managers have raised issues regarding smoke 89 emissions impeding their ability to use prescribed fire (Wolcott et al. 2007). Smoke emissions 90 can potentially influence both those near the treatment site and those far removed as weather

91 patterns disperse smoke across the landscape. As Pyne et al. (1996) note, smoke emissions are

92 often the most visible impact for the public, can threaten public health, and the resulting air

93 quality impacts can lead to restrictions on prescribed burning opportunities to maintain

94 compliance with air quality standards.

95 Limited scholarship has specifically emphasized smoke, with much research including 96 only a few questions about beliefs or attitudes toward smoke within a broader study focused on

97 acceptance of fuels treatments; in most cases, attitudes toward smoke were largely included as an 98 explanatory variable of treatment acceptance. However, Ryan and Wamsley (2008) found that 99 concerns about smoke may be alleviated by increased knowledge of prescribed fire, suggesting 100 that outreach programs describing their beneficial outcomes may not only contribute to increased 101 understanding and acceptance of prescribed fire but also decreased concerns about adverse 102 effects, such as smoke. Through a series of focus groups on smoke emissions and management, 103 Weisshaupt et al. (2005) illustrated that attitudes toward smoke were still largely malleable.

104 While several focus group participants acknowledged smoke emissions were part of life in WUI 105 areas, many formed their attitudes toward smoke throughout the discussions. Based on these 106 focus groups, a number of factors influenced tolerance for emissions: the source of smoke (forest 
107 burning was generally preferable to agricultural burning), the ability to manage emissions from

108 prescribed fire and potentially reduce emissions from a later wildfire, and recognition that

109 prescribed burns would result in ecological benefits.

110 The importance of these factors for tolerance of smoke emissions has been demonstrated

111 across additional studies, with some important differences. Recent studies have also found that

112 smoke tolerance is impacted by the smoke source, however the most acceptable source varied

113 from fires started by lightning strikes (Blades et al. 2014) to wildfires under active suppression

114 (Engebretson et al. 2016) to uncontrolled wildfires (Olsen et al. 2017). Present in each of these

115 studies, however, was a moderate to high level of tolerance (or acceptance) of smoke emissions,

116 including those from prescribed-natural fires and prescribed burns. Once again in line with

117 Weisshaupt et al. (2005), Olsen et al. (2017) found higher acceptance when the fires were

118 expected to benefit society rather than individuals (e.g., agricultural or pile burns). In addition to

119 the origin of the smoke, a number of other tolerance influencers emerged. Blades et al. (2014)

120 found that tolerance was impacted by public warning in advance, expected severity of health

121 effects from the smoke (particularly at unhealthy levels for everyone or sensitive populations),

122 and smoke duration. Higher levels of tolerance emerged if resource managers openly stated the

123 forest health objectives behind the prescribed fire event (Engebretson et al. 2016). While

124 dependent on the fire source, Olsen et al. (2017) found acceptance generally influenced by risk

125 perceptions of smoke, confidence in managers, expected benefits of the fire, and demographic

126 characteristics, including age, education, and rural or urban residence. Lastly, those with

127 previous negative health effects from smoke were generally less tolerant (Blades et al. 2014;

128 Engebretson et al. 2016), but some evidence indicates that health concerns are strongly important 
129 for only a subset of the population, such as those with existing medical conditions (Olsen et al. 130 2017).

131 Based on the importance of information for WUI residents, both in terms of awareness of

132 fire events and in shaping attitudes toward smoke emissions and prescribed fires, a better

133 understanding of how residents interact with information is needed. The Risk Information

134 Seeking and Processing (RISP) model enables us to explore one aspect of this relationship, 135 motivations to seek information.

137 Risk Information Seeking and Processing (RISP) model

A risk is defined as "the chance, within a time frame, of an adverse event with specific

139 consequences" (Burgman 2005, p. 1). Risk perceptions, then, are intuitive judgments about a 140 risk that are dependent on two general components: 1) how much the hazard is feared or how 141 catastrophic the outcomes are likely to be (dread) and 2) how much is unknown about the hazard 142 (Burgman 2005; Slovic 1987). For this study, we consider smoke emissions to be a risk.

143 To understand what motivates individuals to seek additional information regarding

144 perceived risks, communication scholars developed the Risk Information Seeking and Processing 145 (RISP) (Griffin et al. 1999; Kahlor et al. 2006; Trumbo 1999). The RISP (Figure 1) model was 146 originally intended to address direct personal risks (risks with firsthand impacts on an individual, 147 such as drinking contaminated water or experiencing floods) and was based on two existing 148 theoretical models: the Heuristic-Systematic Model (HSM) and the Theory of Planned Behavior 149 (TPB). Briefly, the HSM conceptualizes differences across how much effort is used to process 150 information: slowly and thoroughly using systematic processing or more economically relying 151 on shortcuts (e.g., message characteristics or source identity) with heuristic processing (Eagly 
152 and Chaiken 1993). The TPB examines the factors which influence an individual's decision to

153 engage in a specific behavior, including intentions to act, perceived control over a behavior,

154 beliefs about success or failure, normative beliefs, and motivation to follow the expectations of 155 referents (Ajzen 1991).

The RISP model describes the theoretical relationship between several variables that are conceptualized to influence information seeking and processing behaviors (described in Table 1):

159 individual characteristics, perceived hazard characteristics, affective response, informational

160 subjective norms, information (in)sufficiency, relevant channel beliefs, perceived information

161 gathering capacity, information seeking, and information processing.

164 within the context of health risks related to environmental issues (e.g., Clarke 2009; Griffin et al.

165 1999; Kahlor et al. 2003; Trumbo 1999). Recent work has also examined the model in the

166 context of impersonal risks, or those that focus on societal-level impacts (Kahlor et al. 2006).

167 This has relevance to our study as smoke emissions can be perceived as leading to both personal

168 (e.g., causing breathing issues for an individual) and impersonal (e.g., aesthetic degradation

169 within an area) impacts. Additionally, while much of the previous RISP related research has

170 focused on the information seeking and processing behaviors of the general public (e.g., Griffin

171 et al. 1999; Griffin et al. 2008; Kahlor et al. 2006), this project provides an opportunity to test the

172 RISP model applied to a more knowledgeable public. That is, prior research has found that

173 many WUI residents like those in our study generally recognize the complexity of fuel hazards

174 and have a sophisticated understanding of prescribed fires and fire risks (e.g., Brunson and 
175 Shindler 2004; Toman et al. 2014), although level of engagement in the issue can vary across

176 communities (Paveglio et al. 2015). In this study we focus on the information seeking behaviors

177 regarding smoke emissions and management for residents of select WUI areas (we do not assess

178 information processing). Based on the relationships outlined in the RISP model, we propose the 179 following hypotheses $(H$; Figure 2$)$ : H1: Individual characteristics (i.e., age, gender, acceptability of smoke) significantly influence perceived hazard characteristics. H2: Perceived hazard characteristics (i.e., smoke impact likeliness, smoke impact severity, impact in next five years, proximity) positively influence affective response. H3: Affective response positively influences information (in)sufficiency. H4: Informational subjective norms positively influences information (in)sufficiency. H5: Perceived information (in)sufficiency positively influence information seeking intent. H6: Relevant channel beliefs (i.e., number of sources, source usefulness, state information score, and federal information score) significantly influence information seeking intent.

H7: Perceived information gathering capacity positively influence information seeking intent.

\section{Methods}

The data reported here were collected as part of a broader study on acceptance of smoke 195 emissions and influencing factors in four locations across the US. The study locations include

196 human populations in close proximity to fire dependent ecosystems where active fuels reduction 197 programs are underway to reduce the likelihood of fire and restore forest conditions (Evans et al. 
198 2011; Summers et al. 2011). Accordingly, residents are likely to have previous experience with

199 fire and smoke emissions and view these topics as highly relevant. The specific sites were

200 selected due to their proximity to substantial WUI communities, active fuels reduction programs,

201 recent wildland fire activity, and the diversity of locations and forest and fire ecology

202 represented. Data reported here come from four study locations comprising communities

203 adjacent to the following National Forests:

204 1. Shasta-Trinity National Forest. Located in northern California, this National Forest

205 consists of chaparral and conifer forests. Fire regimes in this forest include both

206 infrequent, stand-replacing fires and frequent, low to moderate severity fires (Evans et al.

207 2011; Summers et al. 2011).

208 2. Kootenai National Forest. Located in northwest Montana, this National Forest consists

209 of mixed conifer forests including douglas-fir, lodgepole pine, and spruce-fir. Fire

210 regimes include a mix of infrequent, low to stand-replacing severity fires (Evans et al.

211 2011; Summers et al. 2011).

212 3. Fremont-Winema National Forest. Located in southern Oregon, this National Forest

213 consists of ponderosa, lodgepole pine, and mixed conifer forests. The ecosystem

214 experiences moderate frequency, low to mixed severity fires (Evans et al. 2011; Summers

$215 \quad$ et al. 2011).

216 4. Francis Marion Ranger District of the Francis Marion and Sumter National Forests.

217 Located in southeastern South Carolina, this National Forest consists of longleaf pine and

218 hardwood forests and the fire regime consists of high frequency, low severity fires

219 (Summers et al. 2011). 


\section{Research design}

222 This study uses data collected from a mail-back/internet survey, based on a random

223 sample purchased from a professional sampling company. The sample consisted of adult

224 residents (ages 18 and older) from counties containing the National Forests, and included a 50/50

225 mixture of rural and urban zip codes (with the exception of Montana, as there was no nearby

226 urban area). Conducted between March and June 2012, the survey followed a modified "tailored

227 design method" (Dillman et al. 2009). First, the participants received a postcard notifying them

228 of the coming survey instrument packet, followed by a complete survey instrument packet (cover

229 letter, questionnaire, and pre-paid postage return envelope) a few days later. The cover letter

230 also contained a link to an online version of the survey instrument. Two weeks later, a reminder

231 postcard went to those who had not yet responded, followed by a second complete survey

232 instrument packet three weeks later. No incentive was provided to participate in the study.

233 A total of 4,800 questionnaires $(1,200$ per site) were mailed to residents, which decreased

234 to an adjusted sample size of 4,325 after correcting for non-deliverables (approximately $10 \%$

235 were returned with incorrect addresses). Of these, 992 questionnaires were completed; nearly all

236 were returned by mail with only $9 \%$ of the questionnaires completed online. The overall,

237 adjusted response rate for the survey was $23 \%$ and varied from a high of $30 \%(N=323)$ in

238 Montana to a low of $13 \%(N=147)$ in South Carolina. To assess whether respondents were

239 representative of the larger populations within the study areas we compared demographic

240 characteristics of respondents to the general population in the sampled counties (United States

241 Census Bureau 2015). Respondents were reasonably similar in race and income to the larger

242 population; however, the results show a modest oversampling of males and a notable

243 oversampling of older adults and those with more education. Gender, age, and education bias is 
244 fairly common in survey research, particularly on natural resources topics (Gigliotti and Dietsch 245 2014; Jacobson et al. 2007).

247 Data analysis

248 Based on mean comparisons (using a Tukey post-hoc correction) of demographic traits

249 across sites, participants were similar in terms of gender and level of education (Table 2). Some

250 differences emerged for age (on average, respondents in South Carolina were younger) and for

251 household income (respondents in Montana had lower incomes compared to California and

252 South Carolina, while Oregon was lower than South Carolina). Given the mixed evidence

253 concerning geographic differences in attitudes toward fuels management (for a review, see

254 Toman et al. 2014) and that the purpose of this paper is to explore the information seeking

255 behaviors of diverse residents in fire dependent ecosystems with active fuels reduction programs,

256 we do not believe these demographic differences are detrimental to the analyses and data were

257 aggregate across all of the study sites. For each of the tested models, the sample size was within

258 an acceptable range for the sample size to estimated parameter ratio recommended for path

259 analysis (Kline 2015). Path models were developed using the Linear Structural Relations

260 (LISREL) software to investigate relationships between variables as described in the RISP

261 model. Path analysis is used to test a series of relationships, including both direct relationships

262 (assessing the influence of variables on immediately subsequent variables) and mediated

263 relationships (where independent variables are proposed to influence dependent variables

264 indirectly through an additional variable) (Kline 2015). A total of four RISP models were

265 developed and tested: one that closely followed the relationships described in the RISP model

266 and three additional models designed to better fit the data. 
The goodness of fit for each model was examined through several measures including:

268 modified chi-squared $\left(X^{2} / d f\right)$, Root Mean Square Error of Approximation (RMSEA), and

269 Comparative Fit Index (CFI) (Hu and Bentler 1999; Kline 2015; Steiger 1990). For the modified

270 chi-squared test, a value of less than five $\left(X^{2} / d f<5\right)$ indicates a good fit, values between five and

271 ten are considered acceptable, and values above ten are inadequate $\left(X^{2} / d f>10\right)$ (Kline 2015).

272 For the RMSEA measure, values less than 0.05 indicate a very good model fit, values in the

273 range of 0.05 to 0.08 indicate a good or reasonable fit, while values above 0.10 indicate a poor fit

274 (Steiger 1990). Finally, for the CFI measure, a value of one represents a "perfect" fit, while

275 those above 0.90 are considered acceptable ( $\mathrm{Hu}$ and Bentler 1999).

276

277 Measures

278 Each of the RISP variable measures were based on previous RISP model studies (e.g.,

279 Griffin et al. 2008; Kahlor et al. 2006). Most measures used a seven-point scale with a neutral

280 midpoint, and "don't know" responses were excluded list-wise from the analyses. Table 3

281 contains additional information on the scales used to assess each variable. For scales containing

282 three or more items, the internal consistency was measured using Cronbach's alpha with a

283 designated Cronbach's $\alpha=0.70$. The reliability for scales of two items was measured using

284 Pearson correlations, with an acceptable level of $r= \pm 0.3$ and a significance level of $\alpha=0.05$. Of

285 note, 'current knowledge' was self-reported and is a measure of perceived knowledge (Ladwig et

286 al. 2012).

287

- Insert Table 3 About Here -

To ensure the suitability of the variables for path analysis, the skewness and kurtosis

289 measurements were examined; only two variables displayed unacceptable levels of kurtosis and 
290 skewness. 'Proximity to potential fire' had levels of both kurtosis and skewness outside of the

291 normal range while 'impact in next 5 years' had non-normal levels of kurtosis. It is likely that

292 the skewness and kurtosis of each of these variables was influenced by our research design and

293 do not require additional action. By focusing on residents living in fire dependent areas with

294 ongoing fire and fuels management activities, it was extremely unlikely that responses would be

295 normally distributed on either of these items.

- Insert Table 4 About Here -

\section{Results}

298 Respondents were most likely to be male, around 62 years old, and had at least some 299 college education (Table 2). Descriptive information for the RISP variables is provided in Table

300 4. Briefly, respondents indicated acceptance of smoke emissions, had moderate expectations of

301 smoke impact severity, lived very close to areas which might burn $(M=3.44$ miles $)$, and worried

302 about smoke (affective response). Respondents indicated they needed more information than

303 they currently held (information (in)sufficiency) and used few sources to find additional smoke

304 information ( $M=4.76$ out of 16 possible sources). Lastly, respondents were split in their

305 intentions to seek additional smoke information: $29 \%$ of respondents intended to seek more

306 information, $39 \%$ did not intend to do so, and the remaining $33 \%$ did not have any intentions

307 either way.

308 List-wise deletion was employed for missing responses, resulting in an effective sample

309 size of 652 for the path analysis. Assessment of model fit can be found in Table 5. The Baseline

310 Model most closely followed the relationships described in the theoretical RISP model

311 (displayed in Figure 1), but it exhibited poor fit and was not consistent with the observed data

$312\left(X^{2}=1331.41, d f=60, p<0.001, X^{2} / d f=22.190\right.$, RMSEA $\left.=0.180\right)$. Following standard path 
313 analysis procedure, the Baseline Model served as a reference point for the subsequent models.

314 Variables without significant relationships were removed one at a time, beginning with

315 component items which only partially represented their respective RISP variables, and the data

316 was once again tested to examine the impact on fit (Kline 2015; Yang et al. 2010). Testing

317 continued until the model fit measures were acceptable or good and did not improve substantially

318 with further variable removal.

$319-$ Insert Table 5 About Here -Model 1 removed only informational subjective norms

320 resulting in a slight improvement in model fit, although the overall fit was still poor (Table 5).

321 Model 2 removed only the 'smoke impact severity' measure (perceived hazard characteristic).

322 The goodness of fit for Model 2 improved substantially, with the modified chi-squared and

323 RMSEA measures indicating acceptable fits. Model 3 removed both informational subjective

324 norms and 'smoke impact severity,' once again resulting in an improved goodness of fit with

325 modified chi-squared, RMSEA, and CFI values all indicating acceptable fits $\left(X^{2}=231.90, d f=\right.$

$\left.32644, p<0.001, X^{2} / d f=5.270, \mathrm{RMSEA}=0.081, \mathrm{CFI}=0.901\right)$. The RISP Model 3 presented here

327 explained $11.8 \%$ of the variance in information seeking behaviors, $\mathrm{p}<0.001$. See Figure 3 for a

328 diagram of Model 3. As Model 3 best maintained relationships representative of the RISP model

329 while achieving a good model fit, this model was examined in greater depth. A number of

330 significant relationships were found and will be considered in light of the hypotheses.

333 characteristics, 'acceptability of smoke' and 'gender,' had a significant influence on the

334 perceived hazard characteristics 'smoke impact likeliness'. That is, females and those with

335 lower acceptability of smoke were predicted to view smoke as a greater hazard (H1). Next, 
336 affective response was significantly positively influenced by the perceived hazard characteristic

337 'smoke impact likeliness' and negatively influenced by 'proximity to potential fire'; participants

338 who believed they were likely to be impacted by smoke and lived closer to an area that might

339 burn have a higher affective response (H2). Information (in)sufficiency was significantly

340 positively influenced by affective response; individuals who indicated they worry about smoke

341 felt they did not have enough information (H3). However, information (in)sufficiency was also

342 predicted to be influenced by informational subjective norms (H4), but the initial models did not

343 find support for this relationship and the variable was removed from the model.

345 Lastly, information seeking intention was significantly positively influenced by

346 information (in)sufficiency (H5) and the 'number of sources' participants already used to receive

347 smoke information (relevant channel belief; H6), and negatively influenced by information

348 gathering capacity (H7). While significant, information gathering capacity was in the opposite

349 direction than predicted. Respondents who believed they did not currently have enough

350 information, already used more sources of information, and indicated it was difficult to find

351 information intended to seek more smoke emissions information. As these findings indicate, a

352 number of the hypothesized relationships were supported $(H 3, H 5)$ or partially supported $(H 1$,

353 H2, H6).

354 Model 3 provided support for the RISP model as the path analysis relationships were

355 generally consistent with the proposed relationships. While some of the component items of the

356 RISP variables were not significant (e.g., the individual characteristic 'age' or the perceived

357 hazard characteristic 'impact in next 5 years'), all but two of these RISP variables were

358 represented within the model by other variable measures (e.g., the individual characteristic 
359 'acceptability of smoke' or the perceived hazard characteristic 'proximity to potential fire'). As

360 noted above, the RISP variable informational subjective norms was removed to increase the

361 goodness of fit and was not represented in the model. Thus, the hypothesis concerning the

362 relationship between information (in)sufficiency and informational subjective norms was not

363 supported $(H 4)$.

365 Discussion

In this paper, we examined the information seeking behaviors of WUI residents regarding

367 smoke emissions from wild and prescribed fires. Specifically, the Risk Information Seeking and

368 Processing (RISP) model was employed to better understand the underlying variables that

369 motivate information seeking behaviors of residents in the study locations. We find that WUI

370 residents' information seeking behaviors are directly influenced by their perceived information

371 needs, beliefs about their ability to find information, and the number of sources they already

372 draw on for relevant information.

373 Before discussing the main findings from this study, some limitations are considered.

374 First, beyond information seeking behaviors, it is also important to know how individuals

375 process information they receive. This study did not assess information processing and greater

376 understanding of this component is needed to more fully understand how WUI residents interact

377 with risk related information; this component of the RISP model merits investigation in future

378 research. Additionally, our measure of information seeking was based on a self-reported

379 intention to find additional information. A more stringent test of actual information seeking

380 behavior itself may yield different results. Second, the affective response variable was based on

381 a single measure. Although the variable performed well in the analyses, we recommend 
382 employing a more comprehensive measure in future studies. Third, as mentioned previously, the

383 theoretical RISP model proposes a relationship between information (in)sufficiency and

384 information seeking which is moderated by information gathering capacity and relevant channel

385 beliefs. Due to analysis constraints, we were unable to include the moderated relationship and

386 instead predicted a direct relationship between information gathering capacity and relevant

387 channel beliefs, consistent with past research. We suggest testing the full proposed theoretical

388 relationship in subsequent scholarship. Lastly, other measures of individual characteristics,

389 perceived hazard characteristics, and relevant channel beliefs, such as health, past experiences,

390 or trust in the information source, may have important impacts on smoke information seeking

391 behaviors and warrant investigation. With these limitations in mind, several key findings emerge

392 from this analysis that merit further discussion.

393 First, the path analysis generally supported the current RISP literature and the study

394 hypotheses that followed the RISP relationships proposed in previous research (apart from those

395 relationships including informational subjective norms, see above). Notably, the models

396 presented here and in the literature support positive relationships between: 1) perceived hazard

397 characteristics and affective response (H2) (Kahlor 2007), 2) affective response and information

398 (in)sufficiency (H3) (Griffin et al. 2008; Kahlor 2007), and 3) information (in)sufficiency and

399 information seeking (H5) (Griffin et al. 2008; Kahlor et al. 2006).

400 Moreover, as has been found in previous studies, the relationship between information

401 seeking and relevant channel beliefs (H6) was inconsistent (Clarke and McComas 2012; Griffin

402 et al. 2008), with only one of the four components significantly predicting information seeking

403 intentions. Previous research has found relevant channel beliefs to be a weak and inconsistent

404 predictor for information seeking; results elsewhere have not provided evidence of a clear 
405 positive or negative relationship and significance has rarely been found. In part, this is

406 hypothesized to be a result of relevant channel beliefs acting as a direct predictor of information

407 seeking rather than a predictor of the relationship between information seeking and information

408 (in)sufficiency as proposed in the theoretical model (Griffin et al. 2008).

409

A few surprising differences from previous literature were found. Prior studies have

410 demonstrated the expected positive relationship between information seeking and perceived

411 information gathering capacity, with those who believe they are able to find and understand

412 information being more likely to seek it (Griffin et al. 2008). However, a negative relationship

413 was demonstrated in this study, with those who believed it was difficult to find information

414 intending to seek additional information.

415 One possible explanation of this difference could be due to the nature of the risk and the 416 availability of information. While smoke emissions are a concern for residents, there has

417 typically been limited information available on smoke emissions. As such, while residents are

418 motivated to learn more about smoke emissions and management, it may be difficult to find

419 appropriate smoke information. This may cause motivated residents to put forth more effort and

420 search through information only tangentially related to smoke emissions; this interpretation is

421 supported by additional evidence in this study as motivated individuals also drew on a greater

422 number of informational sources. Notably, residents who still intend to seek additional

423 information also already use a large number of informational sources. Alternatively, while the

424 RISP model focuses on those intending to seek information, this finding could indicate that those

425 who believed it was easy to find information have already met their informational needs and,

426 thus, do not feel compelled to seek additional information. Future research should investigate

427 the relationship between information gathering capacity and information seeking intentions. 
As mentioned previously, many of the previous RISP studies have focused on the seeking

429 and processing behaviors of the general public (e.g., Griffin et al. 1999; Kahlor 2007; Kahlor et

430 al. 2006). However, our population of WUI residents is likely to have some awareness and

431 potential experiences with smoke issues and may have already sought information in the past.

432 Some of the differences identified in this work may be due to the previous engagement of our

433 participants with smoke and fire topics.

434 Similar to the differences found with perceived information gathering capacity,

435 informational subjective norms were previously demonstrated to have a positive relationship

436 with information (in)sufficiency (Clarke and McComas 2012; Griffin et al. 2008; Kahlor 2007;

437 Kahlor et al. 2006). Kahlor et al. (2006) found a surprisingly strong relationship between the

438 two variables within the context of an impersonal environmental risk, suggesting that when a

439 hazard does not cause direct personal harm, the expectations of important others may have a

440 greater influence on information seeking behaviors than the risk posed by the hazard. In our

441 case, we did not identify a significant relationship between informational subjective norms and

442 information (in)sufficiency; indeed, removing the informational subjective norms variable

443 resulted in improved goodness of fit. The lack of a significant relationship may be due to the

444 inconsistency between our measures and the theoretical RISP model. Although generally not

445 adhered to in RISP research, the theoretical RISP model proposes informational subjective

446 norms are influenced by individual characteristics (individual characteristics are related only to

447 perceived hazard characteristics in tested models based on Griffin et al. (2008)). It is possible

448 that removing the influence of individual characteristics limited the impact informational

449 subjective norms could have within the model. 
Second, while almost half of our participants indicated that they needed more information

451 about smoke emissions, only $29 \%$ indicated they intended to seek additional information. This

452 finding emphasizes that information seeking intentions depend on more than just perceived

453 information need, likely including various individual characteristics and the relative priority of

454 concern given to smoke emissions. Moreover, while participants generally drew on a small

455 number of information sources and felt it was easy to find smoke emissions information those

456 who intend to seek additional information reported that they were already making use of a

457 number of information sources and believe that information is difficult to find. That is, residents

458 who report the greatest intentions to seek additional information are already engaged in effortful

459 information seeking, but believe relevant information is difficult to find or is not sufficient to

460 meet their information needs. This finding may reflect inconsistencies noted in messages from

461 relevant management agencies identified by smoke management personnel in prior research

462 (Olsen et al. 2014). In addition, the unexpected relationship between information seeking

463 intentions and the 'number of sources' used points to differences in how residents interact with

464 available information, especially for residents with different levels of information seeking

465 intentions.

466 Lastly, the analysis also emphasized the importance of both the direct and indirect

467 relationships among risk perceptions and information seeking. While the perceived hazard

468 characteristics of smoke were found to predict information seeking behaviors, this relationship

469 seemed to be primarily driven by one variable_- 'smoke impact likeliness.' 'Smoke impact

$470 \quad$ likeliness' indirectly influenced information seeking through the affective response and

471 information (in)sufficiency variables, meaning participants who believed they were likely to be

472 impacted by smoke emissions were also more likely to worry about smoke, to need more 
473 information than they had, and to seek additional information. Interestingly, the counterpart of

474 this variable, 'smoke impact severity,' performed poorly in the model and was removed from

475 analysis to improve goodness of fit. A potential explanation for this difference is that residents

476 may view any impact of smoke emissions as equally severe, or undesirable, causing them to

477 focus on whether any smoke impacts at all are likely to occur.

478

\section{Management implications}

Although a large portion of WUI residents in fire dependent areas have heard or read

481 about smoke emissions from fires, this study demonstrates that smoke emissions and their

482 impacts are important to WUI residents. Almost half of the residents indicated they worry about

483 smoke emissions, while almost a third indicated experiencing personal health effects due to

484 smoke in recent years. As such, residents may have a high risk perception of smoke emissions

485 from wild and prescribed fires. As suggested elsewhere, management of smoke emissions can

486 influence public perceptions and support of prescribed fires. Moving forward, smoke emissions

487 are an issue that may need to be addressed to maintain public acceptance of prescribed fire and

488 alleviate residents' concerns.

489 There are several important implications from this research for fire managers in WUI

490 areas. First, although a seemingly straightforward finding, it is important to keep in mind that

491 individual characteristics and risk perceptions will influence how individuals assess smoke

492 emissions and their impacts. There is no universal risk rating among WUI residents, rather,

493 residents will evaluate risks based on their individual circumstances. Prior work suggested

494 managers purposefully engage residents on smoke questions, often emphasizing communication

495 about risks with populations they recognize as being more vulnerable to impacts (e.g., residents 
496 of nursing homes, individuals adjacent to planned burns) (Olsen et al. 2014). Findings here

497 provide additional support for such an approach while also suggesting that perceived information

498 needs may also be driven by variables that are less obvious without more in-depth study of

499 residents and supports the value of social research to develop a more informed understanding of

500 local communities. Second, managers cannot assume that residents who already use multiple

501 information resources do not need any more information. Indeed, findings here suggest that the

502 opposite may be true in some cases as individuals who have used more sources also intend to do

503 additional research and believe it is difficult to find information on smoke emissions. Residents

504 who have already sought information about smoke emissions should not be disregarded as

505 knowing enough about the topic. Finally, these findings indicate that smoke emissions

506 information currently available to residents may not be sufficient, especially in consideration of

507 the large discrepancy between information need and seeking intention. Residents of fire

508 dependent areas are in need, and want, relevant and useful smoke emissions information. 509 


\section{References}

511 Ajzen, I. 1991. The theory of planned behavior. Organizational Behavior and Human Decision 512 Processes 50(2): 179-211. doi: 10.1016/0749-5978(91)90020-t.

513 Blades, J.J., Shook, S.R., and Hall, T.E. 2014. Smoke management of wildland and prescribed

514 fire: understanding public preferences and trade-offs. Canadian Journal of Forest Research

515 44(11): 1344-1355. doi: 10.1139/cjfr-2014-0110.

516 Blanchard, B., and Ryan, R.L. 2007. Managing the Wildland-Urban Interface in the Northeast: Perceptions of Fire Risk and Hazard Reduction Strategies. Northern Journal of Applied Forestry 24(3): 203-208. Bright, A.D., Carlos, A.D., Vaske, J.J., and Absher, J.D. 2007. Source credibility and the effectiveness of firewise information. USDA Forest Service, Northestern Research Station. Brossard, D., and Lewenstein, B.V. 2010. A critical appraisal of models of public understanding of science: Using practice to inform theory. In Communicating Science: New Agendas in Communication. Edited by L. Kahlor and P. Stout. Routledge, New York. pp. 11-39. Brunson, M.W., and Evans, J. 2005. Badly Burned? Effects of an Escaped Prescribed Burn on Social Acceptability of Wildland Fuels Treatments. Journal of Forestry 103(3): 134-138. Brunson, M.W., and Shindler, B.A. 2004. Geographic variation in social acceptability of wildland fuels management in the Western United States. Society \& Natural Resources 17(8): 661-678. doi: 10.1080/08941920490480688.

Burgman, M. 2005. Risks and Decisions for Conservation and Environmental Management. Cambridge University Press, Cambridge, UK.

Chaiken, S. 1980. Heuristic versus systematic information processing and the use of source versus message cues in persuasion. Journal of Personality and Social Psychology 39(5): 752-766. doi: 10.1037//0022-3514.39.5.752.

Clarke, C.E. 2009. Seeking and Processing Information about Zoonotic Disease Risk: A Proposed Framework. Human Dimensions of Wildlife 14(5): 314-325. doi: 10.1080/10871200903096155.

Clarke, C.E., and McComas, K. 2012. Seeking and Processing Influenza Vaccine Information: A Study of Health Care Workers at a Large Urban Hospital. Health Communication 27(3): 244256. doi: 10.1080/10410236.2011.578332.

Dillman, D.A., Smyth, J.D., and Christian, L.M. 2009. Internet, mail, and mixed-mode surveys: The tailored design method. 3rd ed. Wiley \& Sons, Hoboken, N.J.

Doerr, S.H., and Santín, C. 2016. Global trends in wildfire and its impacts: perceptions versus realities in a changing world. Philosophical Transactions of the Royal Society of London B: Biological Sciences 371(1696).

Eagly, A.H., and Chaiken, S. 1993. The psychology of attitudes. Harcourt Brace Jovanovich College Publishers, Fort Worth, TX.

Engebretson, J.M., Hall, T.E., Blades, J.J., Olsen, C.S., Toman, E., and Frederick, S.S. 2016. Characterizing Public Tolerance of Smoke from Wildland Fires in Communities across the United States. Journal of Forestry.

Evans, A.M., Everett, R.G., Stephens, S.L., and Youlz, J.A. 2011. Comprehensive fuel treatment practices guide for mixed conifer forests: California, central and southern Rockies, and the southwest (JFSP Project No. 09-2-01-7). Joint Fire Science Program (JFSP). 
553 Gigliotti, L., and Dietsch, A. 2014. Does Age Matter? The Influence of Age on Response Rates 554 in a Mixed-Mode Survey. Human Dimensions of Wildlife 19(3): 280-287. doi:

$55510.1080 / 10871209.2014 .880137$.

556 Griffin, R.J., Dunwoody, S., and Neuwirth, K. 1999. Proposed Model of the Relationship of Risk Information Seeking and Processing to the Development of Preventive Behaviors.

Environmental Research 80(2): S230-S245. doi: 10.1006/enrs.1998.3940. Griffin, R.J., Yang, Z., ter Huurne, E., Boerner, F., Ortiz, S., and Dunwoody, S. 2008. After the Flood: Anger, Attribution, and the Seeking of Information. Science Communication 29(3): 285 315. doi: 10.1177/1075547007312309.

Hammer, R.B., Stewart, S.I., and Radeloff, V.C. 2009. Demographic Trends, the WildlandUrban Interface, and Wildfire Management. Society \& Natural Resources 22(8): 777-782. doi: $10.1080 / 08941920802714042$. Hu, L.t., and Bentler, P.M. 1999. Cutoff criteria for fit indexes in covariance structure analysis: Conventional criteria versus new alternatives. Structural Equation Modeling: A Multidisciplinary Journal 6(1): 1-55. doi: 10.1080/10705519909540118.

Jacobson, C.A., Brown, T.L., and Scheufele, D.A. 2007. Gender-Biased Data in Survey Research Regarding Wildlife. Society \& Natural Resources 20(4): 373-377. doi:

10.1080/08941920601161387.

Kahlor, L. 2007. An Augmented Risk Information Seeking Model: The Case of Global

Warming. Media Psychology 10(3): 414-435. doi: 10.1080/15213260701532971.

Kahlor, L., Dunwoody, S., Griffin, R.J., and Neuwirth, K. 2006. Seeking and Processing Information about Impersonal Risk. Science Communication 28(2): 163-194. doi: 10.1177/1075547006293916.

Kahlor, L., Dunwoody, S., Griffin, R.J., Neuwirth, K., and Giese, J. 2003. Studying HeuristicSystematic Processing of Risk Communication. Risk Analysis 23(2): 355-368. doi: 10.1111/1539-6924.00314. Keller, C., Siegrist, M., and Gutscher, H. 2006. The Role of the Affect and Availability Heuristics in Risk Communication. Risk Analysis 26(3): 631-639. doi: 10.1111/j.15396924.2006.00773.x.

Kline, R.B. 2015. Principles and practice of structural equation modeling. 4th ed. The Guilford Press, New York.

Ladwig, P., Dalrymple, K.E., Brossard, D., Scheufele, D.A., and Corley, E.A. 2012. Perceived familiarity or factual knowledge? Comparing operationalizations of scientific understanding. Science and Public Policy 39(6): 761-774. doi: 10.1093/scipol/scs048.

McCaffrey, S.M. 2004. Fighting Fire with Education: What Is the Best Way to Reach Out to Homeowners? Journal of Forestry 102(5): 12-19.

McCaffrey, S.M. 2006. Prescribed fire: What influences public approval? USDA Forest Service, Northeastern Research Station.

McCaffrey, S.M., and Olsen, C.S. 2012. Research perspectives on the public and fire management: A synthesis of current social science on eight essential questions (General Technical Report NRS-104). USDA Forest Service, Northern Research Station.

McLeod, J.M., Kosicki, G.M., and Pan, Z. 1991. On understanding and misunderstanding media effects. In Mass media and society. Edited by J. Curran and M. Gurevitch. Edward Arnold,

597 National Interagency Fire Center (NIFC). 2016. Wildland fire statistics. 
Olsen, C.S., Mazzotta, D.K., Toman, E., and Fischer, A.P. 2014. Communicating About Smoke from Wildland Fire: Challenges and Opportunities for Managers. Environmental Management 54(3): 571-582. doi: 10.1007/s00267-014-0312-0.

601 Olsen, C.S., Toman, E., and Frederick, S. 2017. A multi-region analysis of factors that influence 602 public acceptance of smoke from different fire sources. International Journal of Wildland Fire.

603 http://dx.doi.org/10.1071/WF16034

604 Paveglio, T.B., Moseley, C., Carroll, M.S., Williams, D.R., Davis, E.J., and Fischer, A.P. 2015.

605 Categorizing the Social Context of the Wildland Urban Interface: Adaptive Capacity for Wildfire and Community \&\#8220;Archetypes\&\#8221. Forest Science 61(2): 298-310. doi:

C

608 Pyne, S.J., Andrews, P.L., and Laven, R.D. 1996. Introduction to wildland fire : Fire

609 management in the United States. 2nd ed. Wiley, New York.

610 Radeloff, V.C., Hammer, R.B., Stewart, S.I., Fried, J.S., Holcomb, S.S., and McKeefry, J.F. 2005. The Wildland-Urban Interface in the United States. Ecological Applications 15(3): 799805. doi: 10.1890/04-1413.

Ryan, R.L., and Wamsley, M.B. 2008. Public Perceptions of Wildfire Risk and Forest Management in the Central Pine Barrens of Long Island (USA). Australasian Journal of Disaster and Trauma Studies 2008(2).

Shindler, B., and Toman, E. 2003. Fuel Reduction Strategies in Forest Communities: A Longitudinal Analysis of Public Support. Journal of Forestry 101(6): 8-15.

Slovic, P. 1987. Perception of risk. Science 236(4799): 280-285. doi: 10.1126/science.3563507. Slovic, P., Finucane, M.L., Peters, E., and MacGregor, D.G. 2004. Risk as Analysis and Risk as Feelings: Some Thoughts about Affect, Reason, Risk, and Rationality. Risk Analysis 24(2): 311322. doi: 10.1111/j.0272-4332.2004.00433.x.

Steiger, J.H. 1990. Structural Model Evaluation and Modification: An Interval Estimation Approach. Multivariate Behavioral Research 25(2): 173-180. doi:

$10.1207 / \mathrm{s} 15327906 \mathrm{mbr} 2502 \_4$.

Summers, W.T., Coloff, S.G., and Conard, S.G. 2011. Synthesis of knowledge: Fire history and climate change (JFSP Project No. 09-02-1-09). Joint Fire Science Program (JFSP).

Toman, E., Shindler, B., and Brunson, M. 2006. Fire and Fuel Management Communication Strategies: Citizen Evaluations of Agency Outreach Activities. Society \& Natural Resources 19(4): 321-336. doi: 10.1080/08941920500519206.

Toman, E., Shindler, B., McCaffrey, S., and Bennett, J. 2014. Public Acceptance of Wildland Fire and Fuel Management: Panel Responses in Seven Locations. Environmental Management 54(3): 557-570. doi: 10.1007/s00267-014-0327-6.

Trumbo, C.W. 1999. Heuristic-Systematic Information Processing and Risk Judgment. Risk Analysis 19(3): 391-400. doi: 10.1111/j.1539-6924.1999.tb00415.x.

United States Census Bureau. 2015. Community facts, 2011-2015 American community survey 5-year estimates.

Weisshaupt, B.R., Carroll, M.S., Blatner, K.A., Robinson, W.D., and Jakes, P.J. 2005.

Acceptability of Smoke From Prescribed Forest Burning in the Northern Inland West: A Focus Group Approach. Journal of Forestry 103(4): 189-193.

Wolcott, L., O'Brien, J.J., and Mordecai, K. 2007. A Survey of Land Managers on Wildland Hazardous Fuels Issues in Florida: A Technical Note. Southern Journal of Applied Forestry 31(3): 148-150. 
643 Yang, Z.J., McComas, K., Gay, G., Leonard, J.P., Dannenberg, A.J., and Dillon, H. 2010.

644 Motivation for Health Information Seeking and Processing About Clinical Trial Enrollment.

645 Health Communication 25(5): 423-436. doi: 10.1080/10410236.2010.483338.

646 
Table 1. Description of RISP variables.

\begin{tabular}{|c|c|}
\hline RISP variable & Description \\
\hline $\begin{array}{l}\text { Individual } \\
\text { characteristics }\end{array}$ & $\begin{array}{l}\text { These include demographic information or past experiences with a risk. Recent } \\
\text { work has conceptualized individual characteristics as directly influencing } \\
\text { perceived hazard characteristics (e.g., Griffin et al. 2008); this approach was } \\
\text { followed in the present study. }\end{array}$ \\
\hline $\begin{array}{l}\text { Perceived hazard } \\
\text { characteristics }\end{array}$ & $\begin{array}{l}\text { These include individual judgments about a risk or feelings of dread and are } \\
\text { conceptualized to directly influence the individual's affective response; those } \\
\text { who believe they are at greater risk from a hazard are more likely to have a } \\
\text { strong emotional response to that hazard (Kahlor 2007). }\end{array}$ \\
\hline Affective response & $\begin{array}{l}\text { This measures emotional responses to a risk (e.g., fear, worry, anger) and } \\
\text { directly influences information sufficiency (those with a strong affective } \\
\text { response are expected to feel they lack information about the specified hazard). }\end{array}$ \\
\hline Informational & This measures an individual's assessment about the level of knowledge others \\
\hline subjective norms & $\begin{array}{l}\text { expect them to have about a risk. Those who believe they are expected to know } \\
\text { more about the topic are predicted to have a larger information (in)sufficiency. }\end{array}$ \\
\hline Information & Difference between the amount of information an individual desires \\
\hline (in)sufficiency & $\begin{array}{l}\text { (information threshold) to appropriately deal with a risk and his or her current } \\
\text { knowledge. Predicted to influence information seeking and processing } \\
\text { behaviors (moderated by relevant channel beliefs and perceived information } \\
\text { gathering capacity); when the sufficiency threshold is much higher than the } \\
\text { current knowledge, individuals are predicted to seek additional information, use } \\
\text { active seeking, and systematically process information (Kahlor 2007). }\end{array}$ \\
\hline Relevant channel & Individual beliefs about quality of available information sources (e.g., \\
\hline
\end{tabular}


beliefs

Perceived information

gathering capacity

Information seeking

Information processing usefulness, trustworthiness). These beliefs are expected to moderate the relationship between information (in)sufficiency and information seeking and processing behaviors; if individuals believe information is of high quality (relevant channel beliefs), they may be motivated to process it more carefully and put forth more effort (McLeod et al. 1991).

This refers to an individual's beliefs about his or her ability to access and understand the information about a particular risk. Similar to relevant channel beliefs, this is expected to moderate the relationship between information (in)sufficiency and information seeking and processing behaviors; individuals who believe they are capable of finding and understanding information on an issue (perceived information gathering capacity), will be more motivated to actively seek and process information (Griffin et al. 1999; Kahlor 2007; Kahlor et al. 2006).

Efforts to gather information can be passive with information gathered from sources an individual uses on a regular basis or active with an individual expanding his or her efforts to include sources outside of his or her normal information gathering routine.

Received information is either processed systematically (greater effort used to analyze and understand the information) or heuristically (relying on peripheral characteristics of the message, provider, or methods of communication rather than evaluations of the information itself) (e.g., Chaiken 1980). 
Table 2. Descriptive statistics for demographic information.

\begin{tabular}{lccccc}
\hline \multicolumn{1}{c}{ Variables } & All & CA & MT & OR & SC \\
\hline Age (median years) & 62.0 & 64.0 & 61.0 & 61.5 & 57.0 \\
& & & & & \\
& \% & \% & \% & \% & \% \\
\hline Gender (male) & 57.9 & 60.4 & 57.4 & 58.4 & 54.0 \\
Education & & & & & \\
$\quad$ High school or less & 28.1 & 21.0 & 35.2 & 27.5 & 25.9 \\
$\quad$ Some college & 25.9 & 29.6 & 21.9 & 27.9 & 24.4 \\
$\quad$ Bachelor's or Associate's degree & 29.6 & 32.5 & 26.9 & 28.3 & 32.6 \\
$\quad$ Some graduate or graduate degree & 16.5 & 16.9 & 15.9 & 16.4 & 17.0 \\
Personal health effects from smoke & & & & & \\
$\quad$ Any source & 26.7 & 29.4 & 32.6 & 27.3 & 16.0 \\
$\quad$ Prescribed fires & 12.2 & 13.4 & 17.6 & 9.3 & 3.4 \\
$\quad$ Wildfires & 16.0 & 22.4 & 18.9 & 13.1 & 4.1 \\
Worry about smoke & 45.7 & 46.0 & 43.2 & 44.4 & 53.2 \\
Heard or read about... & & & & & \\
$\quad$ Prescribed fires & 93.4 & 93.2 & 96.9 & 92.8 & 87.8 \\
$\quad$ Impacts of smoke & 81.6 & 80.9 & 82.8 & 83.4 & 76.9 \\
Reported information (in)sufficiency & 51.7 & 56.2 & 49.5 & 45.6 & 59.0 \\
Intend to seek additional smoke & & & & & \\
information & 28.5 & 32.2 & 23.2 & 28.2 & 34.6 \\
\hline
\end{tabular}


Table 3. RISP variables, scales, and reliability tests (Cronbach's alpha, Pearson correlation) used in analysis.

\begin{tabular}{|c|c|c|c|c|}
\hline $\begin{array}{l}\text { RISP variables } \\
\text { Component variables }\end{array}$ & Items & Scales & $\begin{array}{l}\text { Cronbach's } \\
\text { alpha }(\alpha)\end{array}$ & $\begin{array}{c}\text { Pearson } \\
\text { correlation } \\
(r)\end{array}$ \\
\hline \multicolumn{5}{|l|}{ Individual characteristic } \\
\hline Age & 1 & Years & - & - \\
\hline Gender & 1 & 0 "Male" and 1 "Female" & - & - \\
\hline Acceptability of smoke & 8 & $\begin{array}{l}7 \text { point; "Strongly disagree" to } \\
\text { "Strongly agree" }\end{array}$ & 0.86 & - \\
\hline \multicolumn{5}{|l|}{ Perceived hazard characteristics } \\
\hline Smoke impact likeliness & 8 & $\begin{array}{l}7 \text { point; "Very unlikely" to "Very } \\
\text { likely" }\end{array}$ & 0.93 & - \\
\hline Smoke impact severity & 8 & $\begin{array}{l}7 \text { point; "No impact" to "Very severe } \\
\text { impact" }\end{array}$ & 0.94 & - \\
\hline Impact in next 5 years & 1 & $\begin{array}{l}4 \text { point; "Very unlikely" to "Very } \\
\text { likely" }\end{array}$ & - & - \\
\hline Proximity to potential fire & 1 & $\begin{array}{l}\text { Miles; } 0 \text { "Right next door (or less than } \\
1 \text { mile)" }\end{array}$ & - & - \\
\hline Affective response & 1 & $\begin{array}{l}7 \text { point; "Strongly disagree" to } \\
\text { "Strongly agree" }\end{array}$ & - & - \\
\hline Informational subjective norms & 2 & $\begin{array}{l}7 \text { point; "Strongly disagree" to } \\
\text { "Strongly agree" }\end{array}$ & - & $0.60 * *$ \\
\hline Information (in)sufficiency & 2 & $\begin{array}{l}200 \text { point; }-100 \text { "Complete knowledge } \\
\text { while needing none" to } 100 \text { "No } \\
\text { knowledge while needing complete " }\end{array}$ & - & - \\
\hline Current knowledge & 1 & $\begin{array}{l}100 \text { point; "Know nothing about } \\
\text { smoke" to "Everything that could }\end{array}$ & - & - \\
\hline Sufficiency threshold & 1 & possibly be known about smoke" & - & - \\
\hline \multicolumn{5}{|l|}{ Relevant channel beliefs } \\
\hline Number of sources & 16 & 16 total sources (summed) & - & - \\
\hline Usefulness of sources & 16 & 5 point; "Not useful" to "Very useful" & 0.93 & - \\
\hline $\begin{array}{l}\text { State information score } \\
\text { (best, enough, and timely } \\
\text { information provision) }\end{array}$ & 3 & $\begin{array}{l}7 \text { point; "Strongly disagree" to } \\
\text { "Strongly agree" }\end{array}$ & 0.96 & - \\
\hline $\begin{array}{l}\text { Federal information score } \\
\text { (best, enough, and timely } \\
\text { information provision) }\end{array}$ & 3 & $\begin{array}{l}7 \text { point; "Strongly disagree" to } \\
\text { "Strongly agree" }\end{array}$ & 0.95 & - \\
\hline $\begin{array}{l}\text { Perceived information gathering } \\
\text { capacity }\end{array}$ & 2 & $\begin{array}{l}7 \text { point; "Strongly disagree" to } \\
\text { "Strongly agree" }\end{array}$ & - & $0.30 * *$ \\
\hline Information seeking behaviors & 3 & $\begin{array}{l}7 \text { point; "Strongly disagree" to } \\
\text { "Strongly agree" }\end{array}$ & 0.70 & - \\
\hline
\end{tabular}


Table 4. One-way ANOVA with Tukey post-hoc correction for RISP variables.

\begin{tabular}{|c|c|c|c|c|c|c|}
\hline RISP variables & $\begin{array}{c}\text { All } \\
\text { Mean }\end{array}$ & $\begin{array}{c}\text { CA } \\
\text { Mean }\end{array}$ & $\begin{array}{c}\text { MT } \\
\text { Mean }\end{array}$ & $\begin{array}{c}\text { OR } \\
\text { Mean }\end{array}$ & $\begin{array}{c}\text { SC } \\
\text { Mean }\end{array}$ & $\boldsymbol{F}$ \\
\hline \multicolumn{7}{|l|}{ Individual characteristic } \\
\hline $\begin{array}{l}\text { Acceptability of } \\
\text { smoke }\end{array}$ & 4.80 & 4.73 & 4.84 & 4.75 & 4.92 & 0.97 \\
\hline \multicolumn{7}{|l|}{$\begin{array}{l}\text { Perceived hazard } \\
\text { characteristics }\end{array}$} \\
\hline $\begin{array}{l}\text { Smoke impact } \\
\text { likeliness }\end{array}$ & 3.67 & 3.71 & 3.62 & 3.61 & 3.80 & 0.55 \\
\hline $\begin{array}{l}\text { Smoke impact } \\
\text { severity }\end{array}$ & 3.47 & 3.50 & 3.40 & 3.46 & 3.57 & 0.34 \\
\hline $\begin{array}{l}\text { Impact in next } 5 \text { year } \\
\text { (4-point) }\end{array}$ & 3.43 & 3.50 & 3.34 & 3.49 & 3.39 & 0.61 \\
\hline $\begin{array}{l}\text { Proximity to potential } \\
\text { fire (miles) }\end{array}$ & 3.44 & 3.56 & $0.61^{1}$ & 4.81 & $7.22^{2}$ & $36.49 * * *$ \\
\hline Affective response & 4.31 & 4.48 & 4.12 & 4.21 & 4.61 & 2.58 \\
\hline $\begin{array}{l}\text { Informational subjective } \\
\text { norms }\end{array}$ & 3.49 & 3.47 & 3.56 & 3.36 & 3.59 & 1.08 \\
\hline $\begin{array}{l}\text { Information (in)sufficiency } \\
\text { (200-point) }\end{array}$ & 7.59 & 9.05 & 6.14 & 5.06 & 12.58 & 2.39 \\
\hline $\begin{array}{l}\text { Current knowledge } \\
\text { (100-point) }\end{array}$ & 58.78 & 58.25 & $61.27^{3}$ & 58.53 & $54.53^{3}$ & $2.80 *$ \\
\hline $\begin{array}{l}\text { Sufficiency threshold } \\
\text { (100-point) }\end{array}$ & 66.12 & 67.18 & 66.99 & 63.34 & 67.10 & 1.33 \\
\hline \multicolumn{7}{|l|}{ Relevant channel beliefs } \\
\hline $\begin{array}{l}\text { Number of sources } \\
\text { (out of 16) }\end{array}$ & 4.76 & $4.93^{4}$ & $5.21^{4}$ & 4.53 & $3.87^{4}$ & $5.24 * * *$ \\
\hline $\begin{array}{l}\text { Usefulness of sources } \\
\text { (5-point) }\end{array}$ & 3.05 & 2.92 & 3.07 & 3.09 & 3.15 & 1.75 \\
\hline $\begin{array}{l}\text { State information } \\
\text { score }\end{array}$ & 3.94 & $3.75^{5}$ & 3.85 & 4.09 & $4.20^{5}$ & $3.92 * *$ \\
\hline $\begin{array}{l}\text { Federal information } \\
\text { score }\end{array}$ & 3.72 & 3.64 & 3.64 & 3.79 & 3.91 & 1.45 \\
\hline $\begin{array}{l}\text { Perceived information } \\
\text { gathering capacity }\end{array}$ & 4.33 & 4.28 & 4.46 & 4.30 & 4.22 & 1.39 \\
\hline $\begin{array}{l}\text { Information seeking } \\
\text { behaviors }\end{array}$ & 3.99 & 4.11 & $3.85^{6}$ & 3.91 & $4.25^{6}$ & $4.11 * *$ \\
\hline $\begin{array}{l}\text { Note: Scales are 7-point, unl } \\
{ }^{1} \mathrm{MT} \text { was significantly lower } \\
{ }^{2} \mathrm{SC} \text { was significantly higher } \\
{ }^{3} \mathrm{SC} \text { and MT significantly dif } \\
{ }^{4} \mathrm{SC} \text { differs from CA }(\mathrm{p} \leq 0.0 \\
{ }^{5} \mathrm{SC} \text { and } \mathrm{CA}, \mathrm{p} \leq 0.05 \\
{ }^{6} \mathrm{SC} \text { and } \mathrm{MT}, \mathrm{p} \leq 0.05\end{array}$ & $\begin{array}{l}\text { otherwi } \\
\text { all othe } \\
\mathrm{all} \text { othe } \\
\mathrm{d}, \mathrm{p} \leq 0 . \\
\text { and } \mathrm{MT}\end{array}$ & $\begin{array}{l}\text { oted; } * * * \\
\text { es, } p \leq 0 \\
\text { es, } p \leq 0 \text {. } \\
.001 \text { ) }\end{array}$ & $.001, * * \mathrm{p}$ & $01,{ }^{*} \mathrm{p} \leq \mathrm{c}$ & & \\
\hline
\end{tabular}


Table 5. Goodness of fit for each RISP model.

\begin{tabular}{cccccccc}
\hline Models & Variables & $\boldsymbol{X}^{2}$ & $\boldsymbol{d} \boldsymbol{f}$ & $\boldsymbol{p}$ & $\boldsymbol{X}^{2} / \boldsymbol{d f}$ & RMSEA & CFI \\
\hline Baseline & 16 & 1331.41 & 60 & $<0.0001$ & 22.190 & 0.180 & - \\
1 & 15 & 1197.83 & 54 & $<0.0001$ & 22.182 & 0.180 & 0.616 \\
2 & 15 & 357.54 & 49 & $<0.0001$ & 7.297 & 0.098 & - \\
3 & 14 & 231.90 & 44 & $<0.0001$ & 5.270 & 0.081 & 0.901 \\
\hline
\end{tabular}

Note: LISREL was unable to provide CFI values for Baseline and Model 2 due to multicollinearity. 
Table 6. Structural equations for RISP Model 3.

\begin{tabular}{|c|c|c|c|c|}
\hline \multirow[b]{2}{*}{ Dependent variable } & \multirow[b]{2}{*}{ Explanatory variables } & \multicolumn{2}{|c|}{ Unstand. Coefficient } & \multirow[b]{2}{*}{$R^{2}$} \\
\hline & & $\boldsymbol{B}$ & $\begin{array}{l}\text { Std. } \\
\text { Error }\end{array}$ & \\
\hline \multirow[t]{3}{*}{ Smoke impact likeliness } & Age & 0.005 & 0.004 & $0.329 * * *$ \\
\hline & Gender & 0.529 & $0.110 * * *$ & \\
\hline & Acceptability of smoke & -0.698 & $0.042 * * *$ & \\
\hline \multirow[t]{3}{*}{ Impact in next 5 years } & Age & -0.002 & 0.004 & $0.003 * * *$ \\
\hline & Gender & 0.135 & 0.114 & \\
\hline & Acceptability of smoke & 0.007 & 0.044 & \\
\hline \multirow[t]{3}{*}{ Proximity to potential fire } & Age & -0.021 & 0.021 & $0.010^{* * *}$ \\
\hline & Gender & 1.085 & 0.574 & \\
\hline & Acceptability of smoke & -0.288 & 0.221 & \\
\hline \multirow[t]{3}{*}{ Affective response } & Smoke impact likeliness & 0.624 & $0.043 * * *$ & $0.248 * * *$ \\
\hline & Impact in next 5 years & 0.038 & 0.050 & \\
\hline & Proximity to potential fire & -0.021 & $0.010^{*}$ & \\
\hline Information sufficiency & Affective response & 2.159 & $0.535 * * *$ & $0.025^{* * *}$ \\
\hline \multirow[t]{6}{*}{ Information seeking } & Information sufficiency & 0.013 & $0.002 * * *$ & $0.118^{* * *}$ \\
\hline & RCB: Number of sources & 0.049 & $0.015 * * *$ & \\
\hline & RCB: Usefulness of sources & -0.010 & 0.051 & \\
\hline & $\begin{array}{l}\text { RCB: Federal information } \\
\text { score }\end{array}$ & 0.064 & 0.054 & \\
\hline & $\begin{array}{l}\text { RCB: State information } \\
\text { score }\end{array}$ & -0.058 & 0.054 & \\
\hline & $\begin{array}{l}\text { Information gathering } \\
\text { capacity }\end{array}$ & -0.137 & 0.037 & \\
\hline
\end{tabular}

Note: ${ }^{* * *} \mathrm{p} \leq .001,{ }^{* *} \mathrm{p} \leq .01,{ }^{*} \mathrm{p} \leq .05$ 


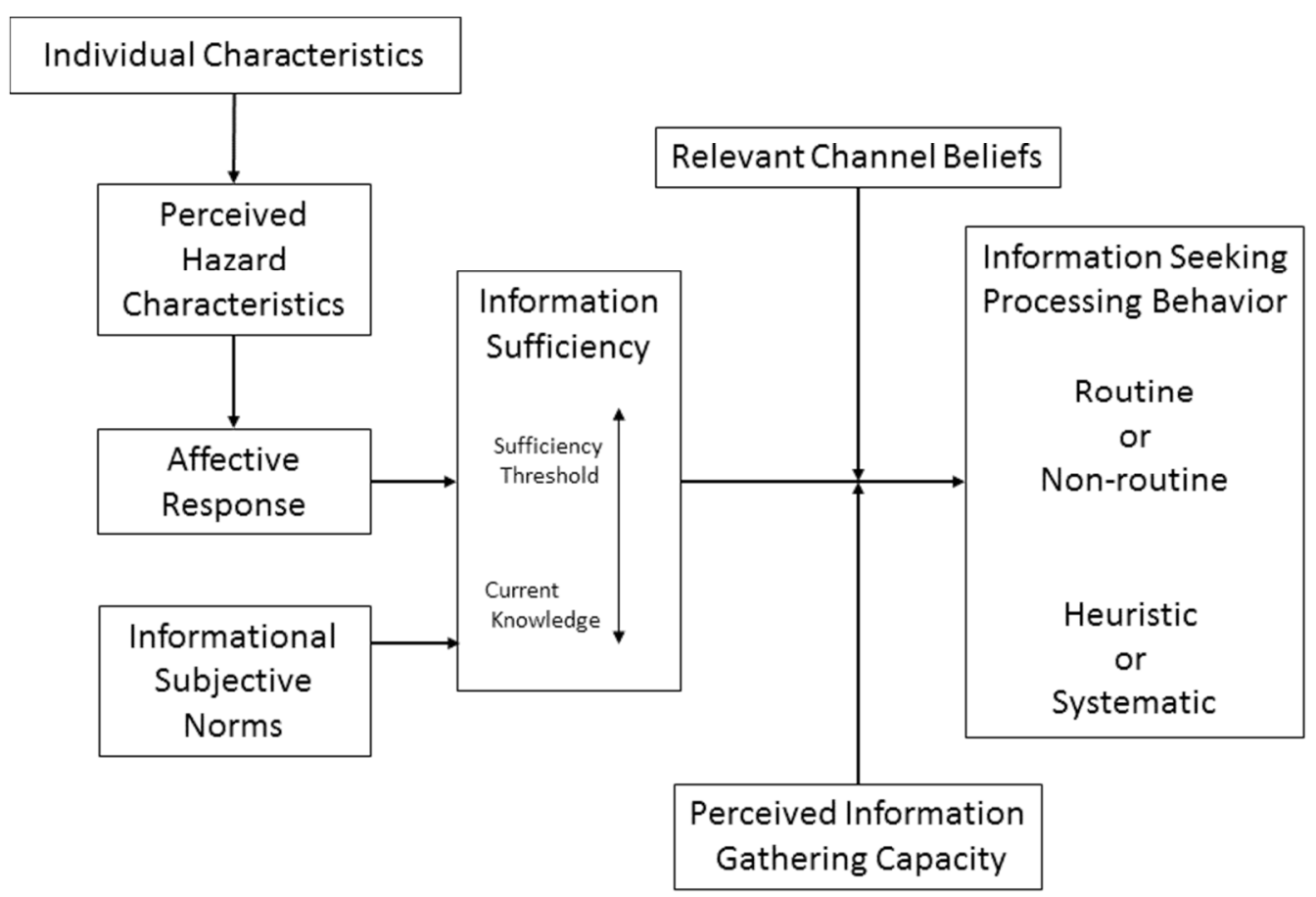

Figure 1. Modified RISP model based on Griffin et al. (2008) showing the relationships between the influences on information seeking and processing behaviors (Griffin et al. 1999). 


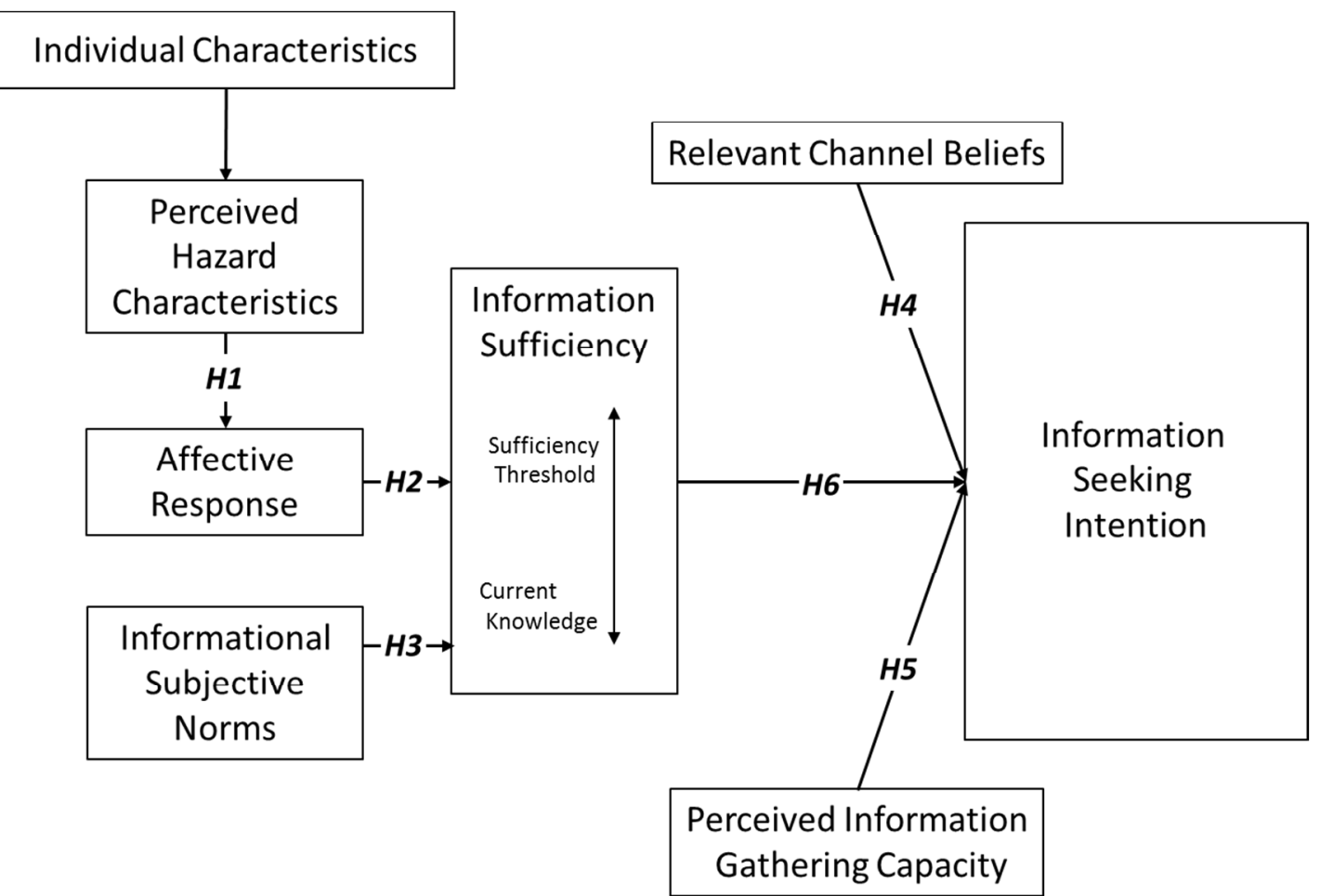

Figure 2. Modified RISP model displaying the relationships tested in the hypotheses. 


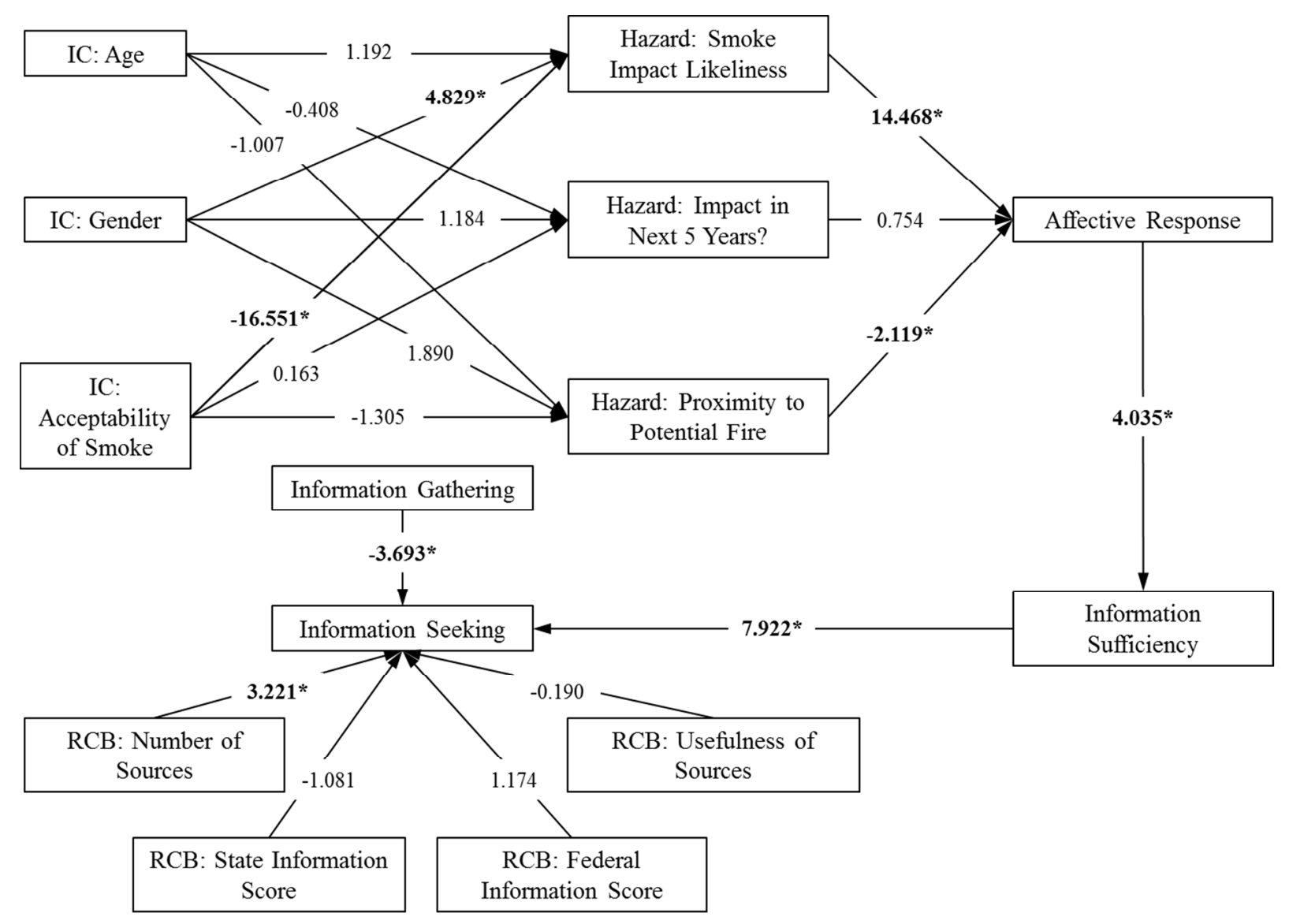

Note: * significance at $p<0.05$ level (and bolded)

Figure 3. Path analysis model explaining information seeking RISP Model 3 with standardized coefficients $(\beta)$;

variables removed are informational subjective norms and smoke impact severity. 